\title{
O Estudo de Impacto de Vizinhança (EIV) nas regiōes Sul e Sudeste do Brasil: avanços e desafios à gestão ambiental urbana
}

\author{
The Neighborhood Impact Study (NIS) in the southern and southeastern regions \\ of Brazil: advances and challenges to environmental urban management
}

Renata Bovo Peres [D [a], Andréia Márcia Cassiano[a]

[a] Universidade Federal de São Carlos (UFSCar), Departamento de Ciências Ambientais, São Carlos, SP, Brasil

Como citar: Peres, R. B., \& Cassiano, A. M. (2019). O Estudo de Impacto de Vizinhança (EIV) nas regiões Sul e Sudeste do Brasil: avanços e desafios à gestão ambiental urbana. urbe. Revista Brasileira de Gestão Urbana, v.11, e20180128. DOI https://doi.org/10.1590/2175-3369.011.e20180128

\section{Resumo}

O Estudo de Impacto de Vizinhança (EIV) é um instrumento de planejamento e gestão que pode atuar preventivamente na análise de impactos urbanos e proposição de medidas de gestão. Lacunas ainda persistem para sua implementação. 0 objetivo do artigo foi apresentar um roteiro metodológico para aperfeiçoamento da regulamentação e elaboração de EIVs. Utilizando-se pesquisa qualitativa, envolveu pesquisa bibliográfica e documental e análises de casos. Inicialmente, identificou-se o panorama da legislação de EIV. Posteriormente, apresentou-se o roteiro metodológico que inclui nove componentes de processo: apresentação da proposta; triagem; determinação do escopo; elaboração; análise técnica; consulta pública; decisão; monitoramento e acompanhamento. Esse roteiro foi verificado em quatorze municípios das regiões sul e sudeste do Brasil. Para superar desafios de ordem técnica, política e administrativa foram indicadas perspectivas de aperfeiçoamentos do EIV. Estas envolvem necessidade de maior orientação de procedimentos; articulação do EIV aos processos de licenciamento urbanístico e ambiental; instrumentalização do poder público na conduta dos processos de empreendimentos; ampliação dos espaços de debates; integração de ações e instâncias federais, estaduais e municipais; constituição de redes entre universidades, municípios e demais setores, visando um trabalho de formação, enfrentamento e renovação da gestão urbana e ambiental do país.

Palavras-chave: Estudo de Impacto de Vizinhança. Planejamento urbano. Políticas públicas. Meio ambiente.

\section{Abstract}

The Neighborhood Impact Study (NIS) is a planning and management instrument that acts preventively at the urban impacts analysis and management proposals. Gaps persist for its implementation. The purpose of the article was to present a methodological roadmap for improving NIS regulation. Using qualitative research, it involved bibliographic and documentary research and case studies. It was initially identified the panorama of NIS legislation. Subsequently, the roadmap was presented, including nine process components: proposal presentation; screening; scope; development of a study; technical analysis; public consultation; decision;

RBP é arquiteta, doutora em Engenharia Urbana, e-mail: renataperes@ufscar.br

AMC é geóloga, doutora em Ciências da Engenharia Ambiental, e-mail: andreiacassiano@yahoo.com.br 
monitoring and follow-up. This script was verified in fourteen municipalities from the southern and southeastern regions of Brazil. To overcome technical, political and administrative challenges NIS perspectives of improvement were indicated. These include the need for greater procedure guidance; the NIS articulation with town planning licensing processes; guidance of public authorities in the conduct of urban development; enlargement of democratic spaces; integration of actions by different governmental institutions; development of networks between universities, municipalities and other institutions aiming at an education, confrontation and renewal of urban and environmental management of the country.

Keywords: Neighborhood Impact Study. Urban planning. Public policies. Environment.

\section{Introdução}

O Estudo de Impacto de Vizinhança (EIV) vem sendo reconhecido no Brasil como um importante instrumento de planejamento e gestão ambiental urbana, que faz parte do processo de licenciamento de empreendimentos e atividades localizados em áreas urbanas e periurbanas (Costa, 2008; Schvarsberg et al., 2016; Cassiano \& Peres, 2017).

Seu objetivo é diagnosticar e prever os impactos de empreendimentos que serão implantados na cidade, além de indicar medidas de prevenção, correção e mitigação. Porém, mais do que somente diretrizes técnicas, ele pressupõe, também, ser um instrumento de mediação de interesses e conflitos entre empreendedores, poder público e comunidades envolvidas. Portanto, três princípios estão presentes em sua fundamentação: o princípio da prevenção, o das funções socioambientais da cidade e da propriedade e o da gestão democrática.

Sabemos, contudo, que os crescentes processos de mercantilização e financeirização, que agem e interferem na produção das cidades brasileiras (Rolnik, 2015; Ribeiro \& Diniz, 2017), movidos por interesses e agentes ligados à esfera privada e pactuados com a gestão pública, vêm favorecendo o capital e desfavorecendo grupos menos privilegiados, fazendo com que leis e instrumentos normativos sejam flexibilizados e negligenciados e a cidade seja palco de inúmeros conflitos socioambientais. Várias são as consequências nefastas desse modelo: o crescimento da especulação imobiliária; os desrespeitos à legislação sob argumentos de interesse público e de urgência; o aumento da informalidade urbana e dos conflitos fundiários (Fernandes, 2013). Quais seriam, então, os limites do Estudo de Impacto de Vizinhança, diante de tal contexto, para que se efetivem questões de ordem técnica mas, sobretudo, resultem em melhorias socioespaciais nos territórios envolvidos?

As origens e influências para a criação e aplicação de EIVs no Brasil derivam de distintos campos do conhecimento (Marques, 2010; Pilotto et al., 2013). A primeira delas advém do campo da Avaliação de Impactos Ambientais (AIA), subsidiada pelos primeiros Estudos de Impacto Ambiental (EIA-RIMA) para grandes empreendimentos hidrelétricos no Brasil.

A segunda influência ocorreu durante o processo de tramitação e negociação dos Projetos de Lei (PL do Senado no 181/1989 e PL da Câmara no 5788/1990) que originaram a criação do Estatuto da Cidade (Lei Federal no 10.257/2001), sobretudo quando o PL 5788 chegou à Comissão de Defesa do Consumidor, Meio Ambiente e Minorias, em 1997. Esta Comissão incorporou o tema da sustentabilidade e apresentou contribuições importantes relativas ao EIV, embora este tenha perdido sua dimensão participativa, que previa a obrigatoriedade de realização de audiências públicas (Schasberg, 2011).

Uma terceira influência no processo de elaboração e criação de EIVs ocorreu na década de 1990, no momento de elaboração de Leis Orgânicas Municipais, que criaram instrumentos de análise de impactos na vizinhança, possivelmente influenciados pelo capítulo da Constituição Federal sobre o meio ambiente ou, ainda, pela Política Nacional de Meio Ambiente (Lei 6.938/1981).

Um quarto movimento decorreu do pioneirismo de alguns municípios que começaram a exigir estudos ambientais para determinadas tipologias de empreendimentos urbanos. Destacam-se, nestes casos, o município de Porto Alegre (com a proposta do Estudo de Viabilidade Urbanística - EVU, em 1978) e o município de São Paulo (com a proposta do Relatório de Impacto de Vizinhança - RIVI, em 1994). 
A despeito desse processo histórico, foi somente a partir de 2001, com a aprovação do Estatuto da Cidade (EC), que este instrumento passou a ser incorporado na prática de gestão de, aproximadamente, $34 \%$ dos municípios brasileiros.

O Estatuto da Cidade definiu, em seus artigos 36 a 38, três diretrizes relativas à aplicabilidade do EIV nos municípios. Uma delas foi a indicação de sete questões mínimas que deveriam ser objeto de análise dos estudos (artigo 37), englobando: adensamento populacional; equipamentos urbanos e comunitários; uso e ocupação do solo; valorização imobiliária; geração de tráfego e demanda por transporte público; ventilação e iluminação, além de paisagem urbana e patrimônio natural e cultural.

A segunda diretriz do EC indicou a exigência de publicidade dos documentos integrantes do EIV, bem como a necessidade de disponibilizá-los para consulta pública (artigo 38). E a terceira diretriz referiu-se à necessidade de regulamentação do EIV a partir de uma lei municipal, que deveria indicar os empreendimentos e atividades sujeitos à elaboração do estudo (artigo 36). Foi com base neste artigo do Estatuto da Cidade que os municípios deram início a um amplo processo de regulamentação do EIV, seja por meio da sua autoaplicabilidade dentro dos planos diretores municipais, seja por meio da criação de leis específicas de EIV.

Contudo, ainda persistem muitas lacunas, desafios e inconsistências quanto à aplicabilidade do EIV por parte das gestões municipais. Uma primeira lacuna, apontada por Hoshino et al. (2014) a partir da análise do município de Curitiba (PR), diz respeito à regulamentação do instrumento. Conforme os autores, a ausência de regulamentação municipal do EIV provoca insegurança jurídica, pois nem os empreendedores, nem os munícipes sabem em que situações é obrigatória a apresentação de estudos, sob quais critérios serão apreciados, que tipo de medidas serão demandadas ou qual o seu trâmite dentro do universo dos órgãos intervenientes.

Tomando como referência a análise sobre o município de São Paulo (SP), Pilotto et al. (2013) também apontam lacunas e desafios do EIV, como: a efetivação de debates e audiências públicas; a necessidade de monitoramento dos impactos avaliados; a articulação do EIV com os demais instrumentos urbanísticos e ambientais e a resistência dos empreendedores em realizarem estudos com qualidade.

Araújo \& Campante (2017) identificam também, a partir do caso de Belo Horizonte (MG), desafios jurídicos, técnicos e político-administrativos. Os aspectos jurídicos envolvem a necessidade de análises integradas de estudos, como o EIV e o EIA e de regulamentação dos procedimentos de consulta aos órgãos setoriais. Os desafios técnicos relacionam-se à melhor definição das áreas de influência dos estudos, cujos limites devem estar vinculados aos impactos identificados; ao maior aprimoramento dos métodos de análise dos impactos e à garantia da dimensão participativa nas fases de elaboração do EIV. Por fim, os aspectos administrativos referem-se à necessária regulamentação do instrumento pelos poderes executivo e legislativo; à melhor estruturação das equipes técnicas locais e à criação de órgãos colegiados, com representação do governo e da sociedade civil, com poder deliberativo sobre a emissão de licenças urbanísticas e ambientais.

Diante do contexto, o objetivo deste trabalho foi apresentar um Roteiro Metodológico de etapas e procedimentos básicos para regulamentação e implementação de Estudos de Impacto de Vizinhança no Brasil, visando contribuir para o aprimoramento da aplicação do EIV e para a gestão ambiental urbana.

Assim, considera-se que o uso deste Roteiro Metodológico possa ser utilizado pelas administrações municipais e por interessados durante o processo de revisão de planos diretores municipais e elaboração de leis específicas de EIV, ou, em outros momentos, de consultas públicas, discussões legislativas e debates a respeito da produção da cidade.

A pesquisa teve uma abordagem qualitativa, envolvendo procedimentos metodológicos de pesquisa bibliográfica, documental e análises de caso. Inicialmente procurou-se compreender o panorama sobre a legislação de EIV no país e o papel do EIV no processo de licenciamento urbanístico e ambiental. Posteriormente, foi apresentado o Roteiro Metodológico para regulamentação e elaboração de EIV, verificado por meio da análise de casos de quatorze municípios das regiões sul e sudeste do país. Por fim, foram traçadas considerações e perspectivas de aperfeiçoamentos desse instrumento, respaldadas pela aplicação do Roteiro nos estudos de caso e pela validação do método em contato com profissionais e especialistas na temática do EIV.

Cabe destacar que os resultados deste trabalho fazem parte do Projeto "Avanços metodológicos em Estudos de Impacto de Vizinhança: contribuições à gestão ambiental urbana", que abrangeu um conjunto de 
pesquisas complementares e realizou eventos e debates sobre a temática do EIV no Brasil. Assim, buscou-se trazer para as reflexões finais deste artigo considerações que advêm dos casos estudados, bem como da integração de experiências práticas e teóricas, que podem contribuir para novos desdobramentos e pesquisas na área.

\section{Panorama sobre a legislação do EIV no Brasil e o papel do EIV no processo de licenciamento de empreendimentos urbanos}

A partir de 2005, o Instituo Brasileiro de Geografia e Estatística (IBGE) começou a publicar, por meio da Pesquisa de Informações Básicas Municipais (MUNIC), informações sobre instrumentos de gestão urbana, incluindo o Estudo de Impacto de Vizinhança. Nesse ano, do total de 5.564 municípios, somente 417 (7,5\%) possuíam legislação específica referente ao EIV. Tratava-se, portanto, de um quadro de pouca aplicação e regulamentação dos instrumentos urbanísticos do Estatuto da Cidade.

Os dados mais recentes da MUNIC 2015 (IBGE, 2016), apresentam uma evolução quanto à previsão de EIV, e demonstram que 34,2\% dos municípios brasileiros possuem legislação de EIV (1.903 municípios), sendo que 540 municípios possuem legislação específica e, em 1.363 municípios, o EIV é parte integrante do plano diretor (Figura 1).

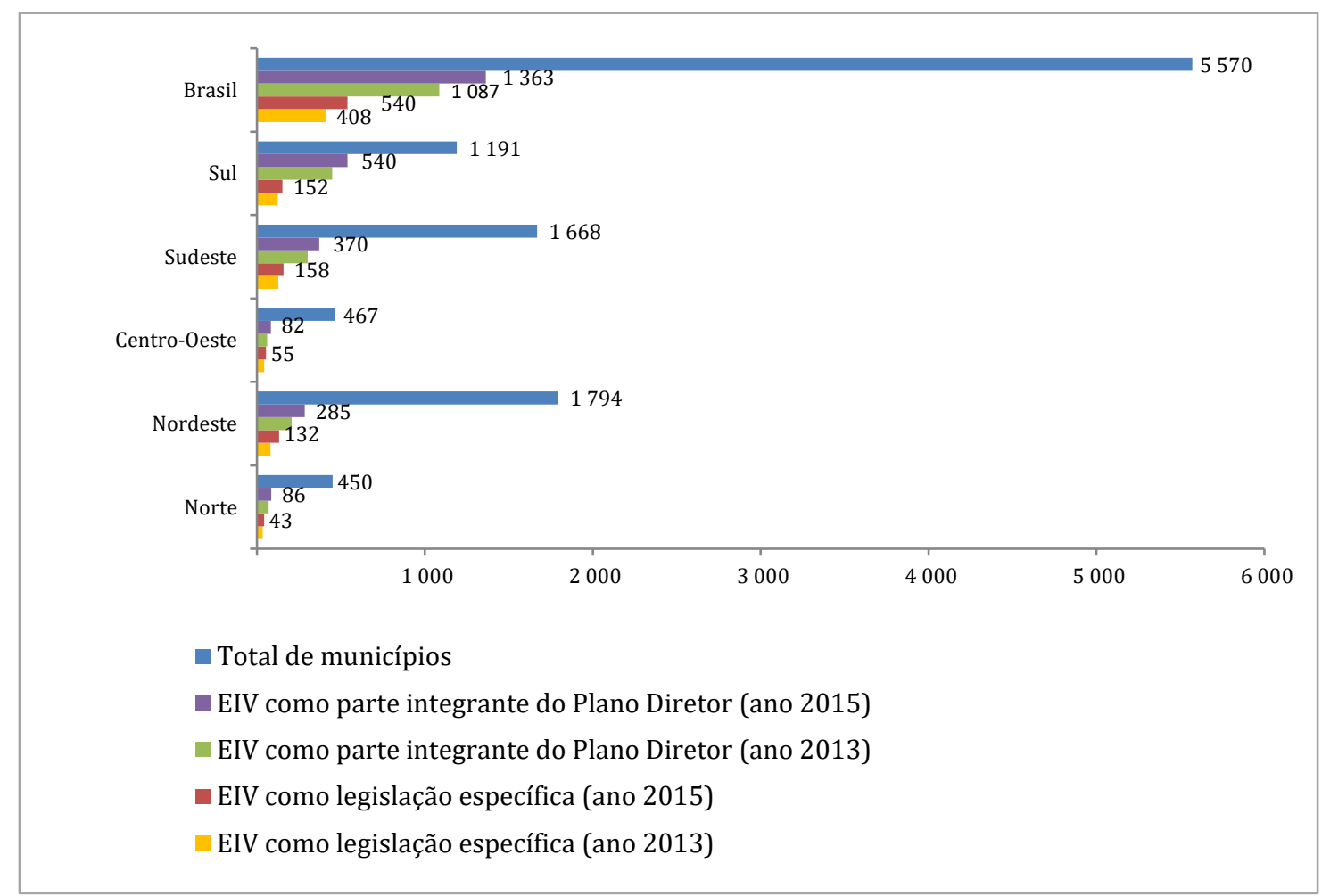

Figura 1 - Quantidade de municípios com EIV no Brasil - 2013/2015. Fonte: IBGE (2014; 2016). Pesquisa de Informações Básicas Municipais 2013/2015.

Ainda que a tendência histórica apresente uma evolução temporal em termos quantitativos, ainda há muito que aperfeiçoar em aspectos técnicos e políticos já destacados, dentre os quais é relevante a questão da melhor compreensão do papel do EIV no processo de licenciamento urbanístico e de licenciamento ambiental de empreendimentos urbanos.

Em tese, para a implantação de qualquer atividade de construção ou novo empreendimento no território urbano brasileiro, exige-se um controle administrativo e uma autorização da gestão pública, mediante o processo denominado licenciamento urbanístico. Esse "controle administrativo" deveria representar um instrumento preventivo que verificasse o atendimento às regras voltadas ao interesse público, tomando como base características físico-ambientais, socioeconômicas e aspirações locais (Ministério Público do Paraná, 2018). 
Contudo, estudos urbanos e territoriais, que analisam os fenômenos da irregularidade jurídica, relacionados aos processos de urbanização brasileiros ressaltam que os procedimentos administrativos de licenciamento urbanístico convivem com um paradoxo: a presença de uma legislação avançada, positivista e moldada a partir de modelos estrangeiros e, por outro lado, um exercício do poder que se ajusta a interesses, sobretudo do mercado imobiliário e do capital, e que empurra grande parte da população para a ilegalidade, gerando a cidade irregular, informal e clandestina (Maricato, 2000; Rolnik, 2000; Quinto Jr, 2003; Fernandes, 2013).

Estudos recentes de Harvey (2014); Ribeiro \& Diniz (2017) e Klink \& Souza (2017) analisam que, na atual fase de expansão financeira do capitalismo, as cidades entraram nos circuitos da valorização financeirizada, fragilizando as capacidades regulatórias nacionais e territoriais.

Compete a cada município determinar as etapas, os procedimentos do licenciamento urbanístico ou ambiental (quando for o caso) e os estudos prévios necessários, que podem ser diferentes em cada local. 0 Estudo de Impacto de Vizinhança representa um desses estudos para os empreendimentos considerados de impacto, tratando-se, portanto, de uma etapa do procedimento de licenciamento, emergindo daí seu valor na abordagem preventiva dos direitos coletivos.

Schvarsberg et al. (2016, p.13) definem que, sob a ótica da mitigação de impactos e do controle social, o EIV deve funcionar como uma ferramenta de apoio ao processo de licenciamento urbanístico, oferecendo ao poder público subsídios para decidir sobre a concessão da licença ou condicioná-la à implantação de medidas compensatórias.

[...] ao incorporar a previsão da exigência de ações condicionantes à emissão da licença, entende-se que o EIV incorpora no processo de aprovação de projetos um olhar "do lote para fora", introduzindo dimensões de análise de natureza urbanística que devem levar em consideração os efeitos de cada empreendimento no território. Tal visão representa um avanço no processo tradicional de licenciamento, no qual se pratica, de modo geral, uma análise voltada "do lote pra dentro", que não considera a integração do empreendimento ao tecido urbano e reduz a emissão da licença a ato administrativo vinculado, na medida em que deve ser sempre concedida na ausência de inconformidade normativa (Schvarsberg et al., 2016, p. 17).

Quanto mais as modalidades de licenciamento (urbanística e ambiental) e seus estudos e instrumentos estiverem integrados, mais favorável torna-se a compatibilização para a prevenção e mitigação dos impactos ambientais urbanos e para o controle social.

Na Figura 2 são apresentadas, de forma esquemática e sintética, as principais etapas de um licenciamento urbanístico municipal.

\begin{tabular}{|c|c|c|c|c|c|c|}
\hline $\begin{array}{l}\text { Solicitação de } \\
\text { Diretrizes. } \\
\text { Abertura do } \\
\text { processo de } \\
\text { Licenciamento } \\
\text { pelo } \\
\text { empreendedor }\end{array}$ & $\begin{array}{l}\text { Emissão de } \\
\text { Diretrizes } \\
\text { pelo poder } \\
\text { público. } \\
\text { Definição de } \\
\text { contrapartidas }\end{array}$ & $\begin{array}{l}\text { Entrega do } \\
\text { Projeto } \\
\text { pelo } \\
\text { empreende- } \\
\text { dor }\end{array}$ & $\begin{array}{c}\text { Análises } \\
\text { Técnicas do } \\
\text { Projeto e } \\
\text { decisões } \\
\text { pelo poder } \\
\text { público }\end{array}$ & $\begin{array}{l}\text { Aprovação do } \\
\text { projeto. } \\
\text { Emissão de } \\
\text { Licenças e } \\
\text { elaboração de } \\
\text { Termo de } \\
\text { Compromisso } \\
\text { (TC) }\end{array}$ & $\begin{array}{c}\text { Fiscalização da } \\
\text { execução da obra } \\
\text { e dos } \\
\text { compromissos. } \\
\text { Emissão de TVO } \\
\text { (Termo de } \\
\text { Vistoria Obras) }\end{array}$ & $\begin{array}{c}\text { Certificado } \\
\text { de } \\
\text { conclusão } \\
\text { da obra. } \\
\text { Emissão do } \\
\text { Habite-se }\end{array}$ \\
\hline
\end{tabular}

Figura 2 - Modelo esquemático das etapas do processo de licenciamento urbanístico. Fonte: Os autores (2018).

A Figura 3 apresenta um esquema de licenciamento urbanístico que incorpora o EIV em seu processo de análise e aprovação de projetos considerados de impacto. 


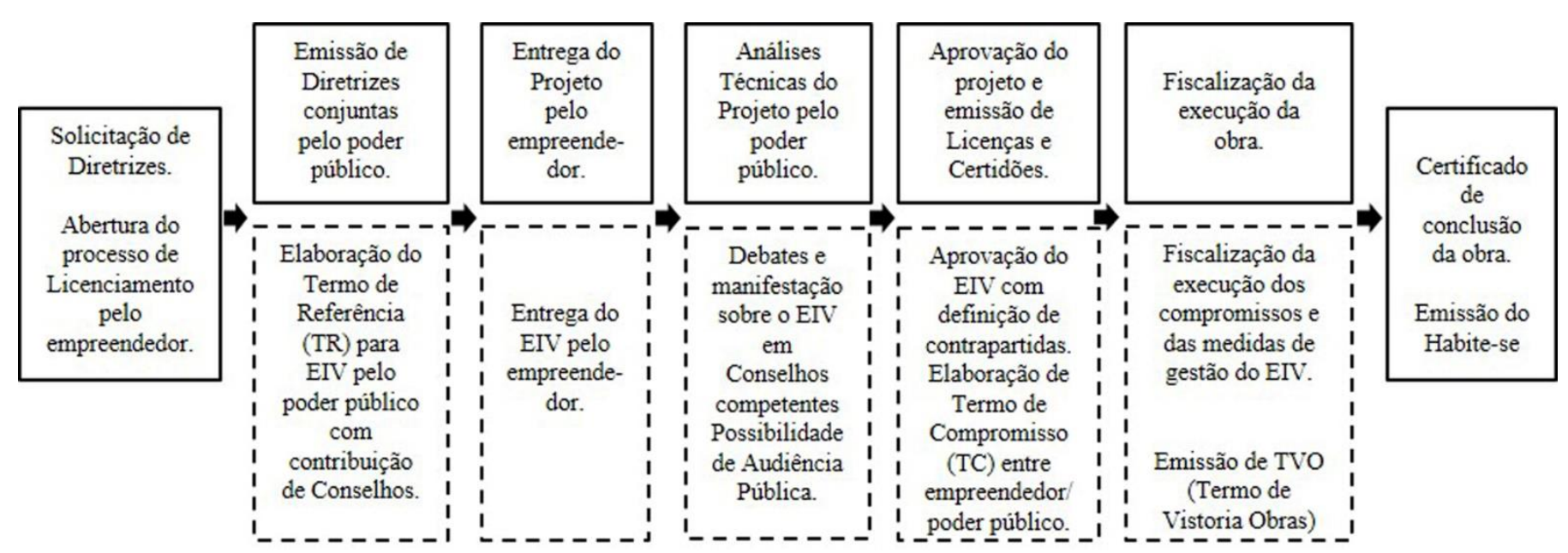

Figura 3 - Modelo esquemático das etapas do processo de licenciamento urbanístico com incorporação do ElV. Fonte: Os autores (2018).

Frequentemente, da maneira como os processos de licenciamento urbanístico vêm incorporando o EIV, algumas etapas se sobrepõem ou são realizadas em ordem inversa, apresentando conflitos na incorporação do instrumento. Um exemplo é a etapa de definição de contrapartidas, que deveria ser realizada após a elaboração do EIV e, geralmente, é definida antes, com base em sugestões de secretários e acordadas pelos empreendedores no momento inicial do projeto. Outro exemplo é a etapa da incorporação de sugestões para o aperfeiçoamento do EIV pelos Conselhos Municipais e pela sociedade civil. Muitas vezes, os debates participativos ocorrem quando o estudo já foi finalizado e analisado, com decisões concluídas pelo poder público. Também a etapa de fiscalização da execução e do cumprimento das medidas mitigadoras definidas no Termo de Compromisso raramente é implementada pelas prefeituras. Tais sobreposições, inversões ou descumprimento de etapas reforçam o senso comum sobre a baixa efetividade do EIV.

Um processo de regulamentação de EIV bem conduzido, que mostre como este instrumento deve ser incorporado ao licenciamento urbanístico ou ambiental, pode ser um caminho que contribua para a integração e aprimoramento da gestão municipal, orientando empreendedores, consultores, técnicos do poder público, representantes de Conselhos Municipais e comunidades envolvidas na melhor compreensão e realização das etapas e dos procedimentos para a elaboração de estudos, análises técnicas e processos participativos.

\section{Proposta de roteiro metodológico para a elaboração e regulamentação de ElV em municípios brasileiros}

Independente da decisão do município de criar uma legislação específica de EIV, ou de ele ser autoaplicável pelo plano diretor, a condução do seu processo de regulamentação pelas gestões municipais não vem contemplando orientações claras e satisfatórias às equipes responsáveis pela elaboração dos estudos, aos técnicos municipais a quem compete a avaliação e, muito menos à sociedade civil, que pouco conhece a efetividade e o alcance desse instrumento, conforme já destacado.

Pensando em uma melhor condução do processo administrativo de elaboração do EIV dentro do sistema de licenciamento municipal, o presente artigo propõe um Roteiro Metodológico para regulamentação $e$ implementação de Estudos de Impacto de Vizinhança. Este Roteiro define nove "Componentes de Processo", que podem ser considerados as etapas e os requisitos mínimos a serem incorporados pelas prefeituras municipais, visando à regulamentação e aplicação do instrumento.

Tomando como aporte conceitual autores como Schvarsberg et al (2016, p. 13) e Sánchez (2013, p. 98), que interpretam o EIV como uma modalidade específica de avaliação de impactos (que podem ser de naturezas diversas: social, econômica, ambiental, urbanística) adaptada a empreendimentos urbanos, a proposta metodológica de construção dos "Componentes de Processo" fundamentou-se, sobretudo, no campo acadêmico relacionado ao Sistema de Avaliação de Impacto Ambiental (AIA). Trata-se de um conceito 
amplamente utilizado, na literatura científica internacional (Glasson, Therievel, Chadwick, 1999; Wood, 2003), na literatura nacional (Sánchez, 2013), bem como em órgãos governamentais. Em diversos países, e também no Brasil, a AIA é o sistema modelo utilizado para o processo de Licenciamento Ambiental em âmbito nacional, estadual e municipal.

Sánchez (2013, p. 105) ressalta que, embora as diferentes jurisdições estabeleçam procedimentos de acordo com suas legislações e particularidades, qualquer Sistema de Avaliação de Impacto Ambiental deve ter um número mínimo de "componentes básicos de processo", sendo: Apresentação da Proposta; Triagem; Determinação do Escopo do Estudo de Impacto Ambiental; Elaboração do Estudo de Impacto Ambiental; Análise Técnica do Estudo de Impacto Ambiental; Consulta Pública; Decisão; Monitoramento e Gestão Ambiental; Acompanhamento; Documentação. Esses componentes definem como serão executadas certas tarefas obrigatórias. 0 debate acadêmico sobre AIA valida a ideia de um processo universal e genérico, que pode ser adaptado às realidades locais de acordo com as necessidades (Glasson, Therievel, Chadwick, 1999).

A adaptação dessa proposta para o processo de regulamentação e implementação de Estudos de Impacto de Vizinhança pode ser considerada positiva e viável, pelo fato de o EIV também necessitar de um conjunto estruturado de procedimentos, por envolver diversos agentes, por ser voltado para a viabilidade socioambiental de uma atividade e por ser instrumento de gestão e de negociação social (Cassiano \& Peres, 2016).

Assim, com base na metodologia de AIA, sintetizada por Sánchez (2013), o Roteiro Metodológico para regulamentação e implementação de Estudos de Impacto de Vizinhança apresenta uma sequência de nove "Componentes de Processo", que podem ser considerados como as principais etapas de implementação do instrumento, a saber: 1) Apresentação da Proposta; 2) Triagem; 3) Determinação do Escopo do EIV; 4) Elaboração do EIV; 5) Análise Técnica do EIV; 6) Consulta Pública; 7) Decisão; 8) Monitoramento e Gestão de Impactos; 9) Acompanhamento. A Tabela 1 apresenta o encadeamento e a síntese explicativa dos "Componentes de Processo".

Tabela 1 - Roteiro Metodológico de Componentes de Processo para regulamentação e implementação de Estudos de Impacto de Vizinhança (ElVs) pelos Municípios

\begin{tabular}{|c|c|}
\hline Componentes de Processo & Procedimentos a serem considerados na elaboração e aplicação das normas \\
\hline $\begin{array}{l}\text { 1. Apresentação da } \\
\text { Proposta }\end{array}$ & $\begin{array}{l}\text { Nesta etapa devem ser indicadas instruções ao empreendedor, ou aos responsáveis pelo } \\
\text { empreendimento, de como iniciar o processo de elaboração do EIV, explicitando: a) o órgão } \\
\text { municipal responsável por receber e protocolar uma nova proposta de atividade ou } \\
\text { empreendimento e por conduzir a análise do EIV; b) o documento específico para o preenchimento } \\
\text { de informações básicas necessárias para triagem de exigibilidade de EIV e os documentos } \\
\text { complementares a serem anexados; c) a comissão ou instância responsável por emitir um Termo de } \\
\text { Referência ou documento norteador para a realização do estudo; d) a participação de conselhos } \\
\text { na elaboração do Termo de Referência; e) o fluxograma sobre as etapas do processo de } \\
\text { licenciamento e a tramitação do EIV; f) formas de publicação, nos meios oficiais de comunicação } \\
\text { do município, da abertura do processo; g) previsão de pagamento de taxa; h) portarias, decretos ou } \\
\text { outras normas que apresentem esses procedimentos. }\end{array}$ \\
\hline 2. Triagem & $\begin{array}{l}\text { Esta etapa deve indicar quais empreendimentos e atividades estarão sujeitos ao EIV e explicitar os } \\
\text { critérios para tal enquadramento, por meio de: a) listas "positivas" por tipologias com critérios de } \\
\text { corte, por tipo ou porte; b) indicação de quadros, tabelas ou mapas que relacionem os tipos e } \\
\text { portes de empreendimentos de impacto com o zoneamento urbano ou demais instrumentos; c) } \\
\text { indicação de tipos de Estudos de Impacto de Vizinhança, se for o caso; d) indicação do poder } \\
\text { discricionário do poder público municipal em casos não previstos. }\end{array}$ \\
\hline $\begin{array}{l}\text { 3. Determinação do } \\
\text { Escopo do EIV }\end{array}$ & $\begin{array}{l}\text { Nesta etapa, devem ser definidas diretrizes que orientem as equipes responsáveis pelos estudos sobre } \\
\text { os conteúdos mínimos dos EIVs, que podem envolver: a) previsão da emissão de um Termo de } \\
\text { Referência ou outro documento norteador para a elaboração do estudo; b) definições de alguns } \\
\text { termos-chave envolvidos nos estudos; c) indicação dos principais itens que os ElVs devem conter } \\
\text { (como: caracterização do empreendimento, delimitação e diagnóstico das áreas de influência, } \\
\text { avaliação dos impactos, proposição de medidas mitigadoras, conclusões, entre outros); d) critérios } \\
\text { para a definição das áreas de influência; e) indicação de componentes, aspectos e impactos que } \\
\text { devem ser analisados no EIV, considerando as questões listadas no art. } 37 \text { do EC e outras não } \\
\text { previstas; f) indicação de métodos para identificação e avaliação de impactos; g) quadros } \\
\text { comparativos relacionando os aspectos e os impactos previstos; h) critérios para a proposição de } \\
\text { medidas preventivas, corretivas ou compensatórias para a mitigação dos impactos negativos em } \\
\text { cada fase do empreendimento; i) previsão de consulta pública. }\end{array}$ \\
\hline
\end{tabular}


Tabela 1 - Continuação...

\begin{tabular}{|c|c|}
\hline Componentes de Processo & Procedimentos a serem considerados na elaboração e aplicação das normas \\
\hline 4. Elaboração do EIV & $\begin{array}{l}\text { Esta etapa especifica como os estudos devem ser elaborados, envolvendo: a) previsão de equipe } \\
\text { multidisciplinar, coordenada por profissional competente com responsabilidade técnica; } \\
\text { b) recomendação de formações específicas para a composição dessas equipes multidisciplinares; } \\
\text { c) cadastros credenciados de profissionais competentes para a elaboração dos estudos; } \\
\text { d) indicação de formato de apresentação do EIV, que pode ser em relatórios completos ou } \\
\text { sintéticos; e) previsão de RIVI (Relatório de Impacto de Vizinhança) e diferenciação dos conteúdos } \\
\text { do EIV e do RIVI, quando for o caso. }\end{array}$ \\
\hline 5. Análise Técnica do EIV & $\begin{array}{c}\text { Nesta etapa devem ser indicados todos os procedimentos de análise dos EIVs, que será realizada } \\
\text { pelas equipes técnicas dos órgãos municipais competentes, contendo: a) indicação do órgão } \\
\text { municipal responsável pela condução da análise do EIV; b) previsão de tramitação da análise do EIV } \\
\text { em outras instâncias municipais; c) definição se a análise do EIV passará por avaliação de conselhos } \\
\text { municipais competentes; d) definição de critérios de análise dos estudos (que podem estar apoiados } \\
\text { nos Termos de Referência ou em documentos norteadores); e) determinação de prazos de retorno } \\
\text { das análises técnicas aos empreendedores e de prazos para pedidos de esclarecimentos; f) previsão } \\
\text { de publicidade dos resultados das análises técnicas nos meios oficiais de comunicação do } \\
\text { município. }\end{array}$ \\
\hline 6. Consulta Pública & $\begin{array}{l}\text { Esta etapa deve estabelecer os mecanismos formais de consulta e participação dos diversos } \\
\text { agentes interessados nos estudos, além da publicização dos documentos e resultados dos EIVS e } \\
\text { devem prever: a) tipos de consulta e participação pública e espaços de debates durante os } \\
\text { diferentes momentos de tramitação dos estudos (como para a definição do Termo de Referência, } \\
\text { para complementação das análises do EIV, para a definição das contrapartidas e medidas de } \\
\text { gestão etc); b) realização de pesquisas de percepção das comunidades do entorno; c) debates } \\
\text { sobre o EIV nos conselhos municipais competentes; d) obrigatoriedade de Audiências Públicas para } \\
\text { determinados tipos de EIVs; e) mecanismos de solicitação de audiências públicas pela população } \\
\text { interessada; f) formas de acesso público a estudos e análises técnicas para consulta prévia; g) } \\
\text { formatos para a realização de consultas e audiências públicas; h) formas de incorporação das } \\
\text { deliberações das audiências nas análises; i) publicidade das convocações e dos resultados das } \\
\text { consultas e audiências nos meios oficiais de comunicação do município. }\end{array}$ \\
\hline 7. Decisão & $\begin{array}{l}\text { Nesta etapa devem-se definir os procedimentos e os modelos para a decisão final dos estudos, } \\
\text { englobando: a) previsão de órgão responsável pela aprovação do ElV e pela emissão do } \\
\text { documento conclusivo (decisão por autoridade); b) previsão de participação de conselhos } \\
\text { municipais para subsidiar a decisão final (decisão colegiada); c) previsão de solicitação de } \\
\text { complementações dos estudos para reanálise antes da decisão final; d) emissão de um } \\
\text { documento/parecer final conclusivo de análise do ElV com previsão de tipos de decisão } \\
\text { (aprovação, não aprovação ou aprovação com indicação de condicionantes e contrapartidas); } \\
\text { e) previsão de prazos para a emissão do documento final do ElV. }\end{array}$ \\
\hline $\begin{array}{l}\text { 8. Monitoramento e } \\
\text { Gestão de Impactos }\end{array}$ & $\begin{array}{l}\text { Esta etapa define as exigências ao empreendedor para a implementação das medidas de } \\
\text { prevenção, redução ou compensação de mitigação dos impactos negativos e potencialização dos } \\
\text { positivos, devendo conter: a) previsão de assinatura de Termo de Compromisso, ou documento } \\
\text { similar, que servirá de título executivo extrajudicial, contendo as medidas preventivas, mitigadoras e } \\
\text { compensatórias, bem como as contrapartidas, com as quais o interessado se compromete a } \\
\text { executar; b) detalhamentos das ações ou dos programas de monitoramento e medidas de gestão } \\
\text { de impactos; c) indicação de responsáveis, prazos, cronogramas, custos etc. }\end{array}$ \\
\hline 9. Acompanhamento & $\begin{array}{l}\text { Esta etapa deve prever os mecanismos de fiscalização e acompanhamento pelo poder público } \\
\text { para a garantia do cumprimento dos compromissos assumidos pelo empreendedor e pelos demais } \\
\text { órgãos intervenientes, envolvendo: a) tipo de órgão ou comissão municipal para acompanhamento } \\
\text { dos compromissos; b) previsão de realização de auditorias, vistorias ou relatórios de } \\
\text { acompanhamento; c) previsão de divulgação desse acompanhamento para esclarecimentos junto } \\
\text { a conselhos ou comunidades interessadas; d) vinculação do cumprimento dos compromissos } \\
\text { assumidos com as etapas finais do licenciamento urbanístico: emissão das licenças de } \\
\text { funcionamento ou dos certificados de conclusão da obra (Habite-se), ou vistorias de entrega. }\end{array}$ \\
\hline
\end{tabular}

Fonte: Os autores (2018).

Ainda que os Componentes do Processo ou etapas representem requisitos mínimos, os procedimentos descritos no Roteiro acima podem ser adaptados para cada realidade municipal, compreendendo suas especificidades e contextos.

Com vistas a verificar a aplicabilidade da proposta deste Roteiro e, ao mesmo tempo, possibilitar uma reflexão a respeito de como municípios brasileiros têm regulamentado suas leis de EIV, expõem-se aqui os resultados do estudo de caso, que envolveu quatorze municípios das regiões Sul e Sudeste do país. 


\section{Análise de casos brasileiros e aplicação do roteiro proposto}

A pesquisa de casos para aplicação do Roteiro e análise de regulamentação de EIVs em municípios brasileiros pautou-se, de início, na identificação e seleção dos tipos de municípios de interesse para a análise em foco. Para tanto, foram levantados estudos de tipologia de municípios (BITOUN; MIRANDA, 2009) e os bancos de dados da MUNIC, realizada em 2003, 2008, 2013 e 2015.

Com base nesses documentos, quatro critérios foram utilizados para selecionar os municípios considerados referência: possuir população acima de 101.000 habitantes (por apresentarem maior dinamismo econômico e regional, além de gestão ambiental avançada); possuir legislação específica de EIV; pertencer às regiões Sul e Sudeste, onde a pesquisa MUNIC indicou maior prevalência de municípios com EIV nessas faixas populacionais e apresentar diversidade de estados dentro das regiões selecionadas. A pesquisa, portanto, focou sua análise em sete municípios com faixa populacional entre 101.000 e 500.000 habitantes e sete municípios acima de 501.000 habitantes, localizados nas regiões Sul e Sudeste. Na Tabela 2, são apresentados os municípios estudados e as normas legais analisadas.

Tabela 2 - Municípios analisados quanto à regulamentação do Estudo de Impacto de Vizinhança (EIV).

\begin{tabular}{|c|c|c|c|}
\hline Município & Estado & População & Regulamentação de EIV \\
\hline \multicolumn{4}{|c|}{ Grupo 1: população entre 101.000 e 500.000 habitantes } \\
\hline Americana & SP & 210.638 & Lei n 5.011/2010 \\
\hline Betim & MG & 378.089 & Lei $n^{\circ} 5.540 / 2013$ \\
\hline Blumenau & SC & 309.011 & Lei complementar $n^{\circ} 834 / 2011$ \\
\hline Cascavel & PR & 286.205 & Lei nº 6.996/2017 \\
\hline Franca & SP & 318.640 & Lei complementar no 206/2012 \\
\hline Niterói & RJ & 487.562 & Lei $n^{\circ} 2.051 / 2003$ \\
\hline Vitória & ES & 355.801 & Decreto $n^{\circ} 14.243 / 2009$ \\
\hline \multicolumn{4}{|c|}{ Grupo 2: população acima de 501.000 habitantes } \\
\hline Belo Horizonte & $M G$ & 2.502 .557 & $\begin{array}{c}\text { Decreto } n^{0} 14.594 / 2011 \\
\text { Lei } n^{\circ} 10.637 / 2008 \text {, Lei } n^{\circ} 12.236 / 2015 \text {. Decretos } n^{0} \text {; }\end{array}$ \\
\hline Londrina & PR & 548.249 & $1385 / 2015$ e $356 / 2017$ \\
\hline Porto Alegre & RS & 1.476 .867 & Lei complementar $n^{\circ} 695 / 2012$ \\
\hline Santo André & SP & 710.210 & Lei no 8.696/2004; Lei 9.394/2012 \\
\hline São Bernardo do Campo & SP & 816.925 & $\begin{array}{l}\text { Lei 5.714/2007, Dec. 16.477/2008 e Res. SG/SP n 1/2008 } \\
\text { Dec. } n^{\circ} 34713 / 1994 \text { e 36613/1996. Projeto de Lei }\end{array}$ \\
\hline São Paulo & SP & 11.967 .825 & $414 / 2011$ \\
\hline Uberlândia & $M G$ & 662.362 & Lei complementar $n^{\circ} 519 / 2010$ \\
\hline
\end{tabular}

Fonte: Os autores (2018).

Identificadas as faixas populacionais e os municípios representativos, a pesquisa procurou analisar as legislações de EIV dos casos selecionados. Para tal análise, estudos de avaliação de políticas públicas contribuíram na fundamentação metodológica (Ipea, 2018; Pólis, 2006; Bucci et al., 2001). De acordo com o Instituto Pólis (2016, p. 2), para que uma política pública se concretize, há o desenvolvimento de um ciclo composto por cinco fases: 1) a identificação de uma questão a ser resolvida; 2) a formulação de um plano de ação; 3) a decisão e a escolha das ações prioritárias; 4) a implementação através de leis e procedimentos administrativos; 5) a avaliação dos resultados alcançados.

Este trabalho focou sua análise na etapa de "implementação através de leis de EIV nos municípios", que foi feita por meio de consultas ao conjunto de normas (leis, decretos, projetos de leis) em sites das prefeituras e câmaras municipais; seguidas de análise documental qualitativa e exploratória, considerando-se os nove "Componentes de Processo", descritos na Tabela 1. Ressalta-se que não foi foco da pesquisa a avaliação da aplicação da gestão dessas normas nos municípios, bem como os reflexos socioespaciais decorrentes da aplicação do EIV.

A forma de avaliação das legislações de EIV nos municípios considerou uma sequência de perguntas norteadoras relativas às nove etapas dos "Componentes de Processo", estruturadas em um checklist (adaptado de Ipea, 2018). Seguindo-se o Roteiro Metodológico de Componentes de Processo, foram analisadas a previsão ou não das nove etapas, bem como a existência de procedimentos relacionados a cada uma delas. Assim, a partir da análise da constatação de "Presença", "Presença parcial" ou "Ausência" dos Componentes de Processo nas legislações municipais que tratam de EIV, foi elaborado um quadro analítico qualitativo (Tabela 3) e, a seguir, foram tecidas considerações a respeito. 
Tabela 3 - Síntese da análise da regulamentação de EIV em quatorze municípios brasileiros, considerando o Roteiro Metodológico de Componentes de Processo

\begin{tabular}{|c|c|c|c|c|c|c|c|c|c|}
\hline $\begin{array}{l}\text { Componentes Básicos para } \\
\text { Regulamentação de EIV }\end{array}$ & 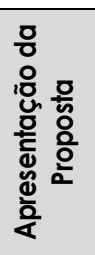 & $\begin{array}{l}\text { E } \\
\text { o } \\
\text { 을 }\end{array}$ & $\begin{array}{l}\text { 뻐 } \\
\text { 응 } \\
\text { 응 } \\
\text { uㅐ }\end{array}$ & 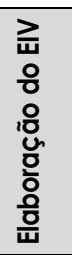 & 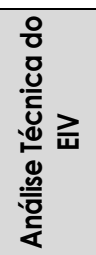 & 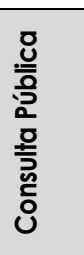 & 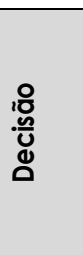 & 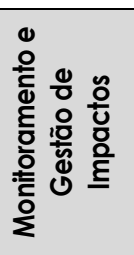 & 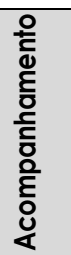 \\
\hline \multicolumn{10}{|c|}{ Grupo 1: municípios com população entre 101.000 e 500.000 habitantes } \\
\hline Americana & $+/-$ & $+/-$ & $+/-$ & $+/$ & - & $+/-$ & + & + & + \\
\hline Betim & $+/-$ & $+/-$ & $+/-$ & $+1-$ & - & $+/-$ & + & + & + \\
\hline Blumenau & + & + & + & + & + & + & + & + & + \\
\hline Cascavel & - & + & + & - & $+/-$ & + & + & $+/-$ & $+1-$ \\
\hline Franca & - & - & $+/-$ & + & - & + & - & - & - \\
\hline Niterói & $+/-$ & $+/-$ & + & + & + & + & + & $+/-$ & - \\
\hline Vitória & + & $+/-$ & + & + & + & + & + & + & + \\
\hline \multicolumn{10}{|c|}{ Grupo 2: municípios com população acima de 501.000 habitantes } \\
\hline Belo Horizonte & + & $+/-$ & + & + & + & $+/-$ & + & + & + \\
\hline Londrina & + & $+/-$ & + & + & + & $+/-$ & + & + & + \\
\hline Porto Alegre & $+/-$ & + & + & + & $+/-$ & + & $+/-$ & + & + \\
\hline Santo André & $+/-$ & $+/-$ & $+/-$ & + & $+/-$ & + & + & + & + \\
\hline São Bernardo do Campo & + & + & $+/-$ & + & $+/-$ & $+/-$ & + & + & + \\
\hline São Paulo & $+/-$ & $+/-$ & $+/-$ & - & + & - & + & $+/-$ & - \\
\hline \multirow[t]{4}{*}{ Uberlândia } & $+/-$ & $+/-$ & $+/-$ & - & - & $+/-$ & + & + & + \\
\hline & + & \multicolumn{8}{|c|}{$\begin{array}{l}\text { Legenda } \\
\text { Presença na regulamentação }\end{array}$} \\
\hline & $+/-$ & \multicolumn{8}{|c|}{ Presença parcial na regulamentação } \\
\hline & - & \multicolumn{8}{|c|}{ Ausência na regulamentação } \\
\hline
\end{tabular}

Fonte: Os autores (2018).

No primeiro grupo, os municípios considerados de destaque, em termos de avanços na regulamentação de EIV, são Blumenau, Vitória e Niterói, devido à previsão de emissão de diretrizes específicas para a elaboração dos EIVs, por meio de emissão de Termos de Referência (TR) por suas Comissões Intersetoriais de Análise, para os quais ainda são explicitados critérios e prazos detalhados. Além disso, há previsão de equipes multidisciplinares para a elaboração do EIV com membros credenciados em suas áreas de atuação e com responsabilidade técnica. Blumenau e Vitória têm maior destaque ainda com respeito à obrigatoriedade de Audiências Públicas, além de possibilidade de ocorrência de debates após a realização destas, no caso de Vitória. Esses dois municípios destacam-se, ainda, na indicação de órgãos responsáveis para recepção e apresentação da proposta para emissão de diretrizes específicas para a elaboração dos EIVs, publicização dos documentos relacionados ao processo, sendo que, quanto à decisão final, incluem deliberação de Conselhos Municipais após emissão dos pareceres técnicos.

No segundo grupo, os destaques são para os municípios de Belo Horizonte e Londrina, em função da previsão de maior número de componentes considerados básicos para a adequada regulamentação dos processos que envolvem EIV. Santo André também merece destaque em relação à política de implementação do EIV, pois busca fazer a integração do licenciamento urbanístico com o ambiental, indicando, para a apresentação da proposta, um fluxograma detalhado de aprovação de projetos, associado a um fluxograma de implantação de empreendimentos de impacto.

Nesta faixa, a exemplo do que foi citado para o primeiro grupo, também tem relevância a previsão de comissões intersetoriais para a emissão de Termos de Referência para EIV (Belo Horizonte e Londrina). Ainda no que se refere à emissão de TRs, Belo Horizonte e Porto Alegre contam com a possibilidade de ciência e possível revisão destes por Conselhos Municipais, o que constitui um grande avanço, visto que, nesses casos, eventuais situações de conflitos e/ou demandas das vizinhanças podem ser consideradas pelos empreendimentos em suas fases iniciais de projeto. Belo Horizonte e Londrina ainda merecem ênfase pelo estabelecimento dos critérios de análise do EIV, empregados por seus grupos de análise, bem como pelos prazos detalhados para todas as fases dos processos de análise desses estudos.

A exemplo do que foi observado para alguns municípios do primeiro grupo, a previsão de participação de Conselhos Municipais na fase de decisão sobre os EIVs, foi considerada na legislação de Belo Horizonte, 
Londrina, Uberlândia e Santo André, o que ganha relevância em função da possibilidade de inclusão de medidas de gestão de impactos que possam atender vizinhanças potencialmente afetadas pelo empreendimento. Todos os demais também consideram como principal mecanismo de acompanhamento a assinatura de Termos de Compromisso, seguido de Emissão de Termos de Conclusão de Medidas e/ou Obras (Belo Horizonte, Londrina, Santo André, Uberlândia), além de previsão de elaboração de relatórios de andamento da implantação pelo empreendedor (Londrina) e vistorias pelo Poder Público Municipal (Belo Horizonte).

A Tabela 4 sintetiza um quadro contendo os "Componentes de Processo" e os principais destaques nas legislações analisadas.

Tabela 4 - Principais destaques nas legislações dos municípios estudados considerando a previsão dos Componentes de Processo de ElV

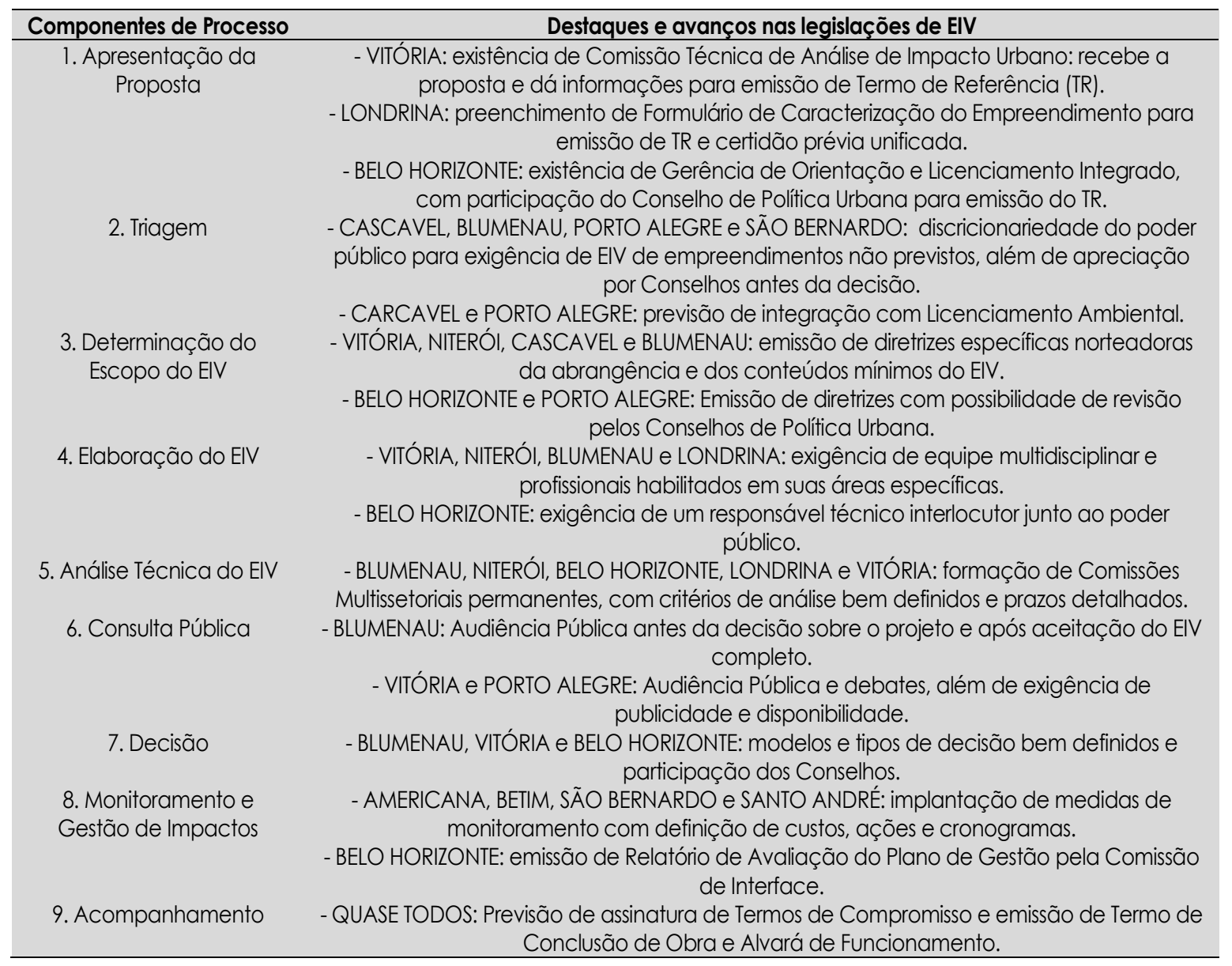

Fonte: Os autores (2018).

O maior número de etapas dos "Componentes de Processo" encontra-se nas legislações dos municípios de faixa populacional acima de 501.000 habitantes, talvez pela maior estrutura institucional, além de maior tempo de existência de Planos Diretores e Conselhos Municipais. Conclui-se que ainda há aspectos que merecem ser aperfeiçoados, sobretudo quanto à necessidade de uma estrutura de análise de EIV com competências, prazos e etapas definidos, detalhamento do escopo do EIV, fiscalização e acompanhamento de contrapartidas e compromissos assumidos e real efetividade das instâncias de participação social.

\section{Perspectivas e necessidades de avanços na temática do EIV no Brasil}

Com base na análise das legislações de EIV dos casos estudados neste trabalho e na construção de uma proposta metodológica de Etapas e Componentes de Processo, destaca-se, para a aplicação e o 
aperfeiçoamento do Estudo de Impacto de Vizinhança no Brasil, a necessidade de superação de desafios de ordem técnica, política e institucional.

Os desafios de ordem técnica devem compreender, sobretudo:

1. Maior orientação, aos diversos interessados e responsáveis, quanto aos fluxos processuais e à implementação do EIV nos municípios, por meio de legislações específicas, portarias, decretos, instruções normativas, Termos de Referência (TR), fluxogramas etc. A proposta do Roteiro Metodológico para a regulamentação e implementação de Estudos de Impacto de Vizinhança pode representar um caminho de contribuição para o aprimoramento deste aspecto.

2. Maior articulação das etapas envolvidas nos Estudos de Impacto de Vizinhança com as etapas envolvidas no processo de licenciamento urbanístico ou de licenciamento ambiental municipal. Nesse sentido, elaboração de fluxogramas integrados, criação de comissões multissetoriais para diretrizes conjuntas de avaliação de projetos, além de consolidação de novos marcos regulatórios urbanístico-ambientais integrados devem ser pensados, com ampliação da capacidade municipal, de modo que enfrentem os interesses conflitantes de órgãos locais e reflitam sobre os modelos de ocupação urbana dos territórios.

3. Ampliação de espaços de debates, formação e capacitação sobre Estudos de Impacto de Vizinhança, em nível municipal, envolvendo técnicos, gestores, consultores, empreendedores, pesquisadores e demais agentes. A Universidade, nesse sentido, pode exercer um papel-chave na realização de Programas de Formação e Extensão com ênfase na capacitação de agentes públicos e sociais, visando o aprimoramento da gestão e da política urbana.

Os desafios de ordem política envolvem questões que devem ser enfrentadas quanto:

À necessidade de maior protagonismo do poder público, fortalecido como instância planejadora, na conduta dos processos de aprovação de empreendimentos urbanos, superando o tradicional favorecimento dos interesses privados e colocando os interesses públicos e as funções sociais da cidade em primeiro plano. Além de regular o uso e ocupação do solo, cabe ao poder público induzir os movimentos do mercado imobiliário, e não ser condicionado por este.

Ao maior diálogo do Estado com a sociedade civil, no sentido da ampliação das formas de participação nos processos de planejamento e gestão urbano-ambiental. As audiências públicas de EIVs não devem ser vistas como uma forma de cumprimento protocolar, mas, sim, de um espaço de pactuação de propostas, que devem trazer mais benefícios do que ônus às comunidades afetadas, bem como aos empreendedores.

Aos espaços de debates de EIVs, que podem impulsionar discussões para além do projeto de um empreendimento específico, e promover a produção da cidade em uma perspectiva sistêmica e integrada da paisagem urbana e rural.

Destacam-se também desafios de ordem institucional que ultrapassam a esfera municipal, sendo necessário:

1. Revalorizar o papel e a ampliação da atuação de instâncias federais quanto a execução, aprimoramento e divulgação dos instrumentos preconizados pelo Estatuto da Cidade. Em 2016, foi lançado o Caderno Técnico de Regulamentação e Implementação do Estudo de Impacto de Vizinhança (Schvarsberg et al., 2016) pelo Programa Nacional de Capacitação das Cidades Capacidades, resultando em um importante material a ser divulgado aos setores que atuam com EIV no país. Em 2017, o Capacidades foi renovado e, em 2018 e 2019, foram promovidos cursos sobre instrumentos do Estatuto da Cidade. Um deles foi o "Curso a distância de autoinstrução sobre Estudo de Impacto de Vizinhança", cujo principal objetivo foi debater e divulgar o Caderno Técnico (Schvarsberg et al., 2016).

2. Fortalecer a atuação do Conselho das Cidades (ConCidades) e das Conferências da Cidade em âmbito nacional, estadual e municipal. Resoluções ConCidades poderiam melhor orientar e definir critérios e diretrizes para a regulamentação de instrumentos urbanísticos, como o EIV. Poderiam, inclusive, ser integradas com Resoluções do Conselho Nacional do Meio Ambiente (Conama).

3. Ampliar o debate sobre os instrumentos de regulação urbana e ambiental, o que pode ser feito em forma de redes conjuntas entre universidades, municípios e instituições nacionais que atuam para o fortalecimento municipal. Exemplos destas instituições são: a Associação Nacional de Órgãos Municipais de Meio Ambiente - ANAMMA, a Rede Social Brasileira por Cidades Justas e Sustentáveis, Observatórios Nacionais e Municipais, entre outras. 


\section{Conclusões}

Debater o aperfeiçoamento e o avanço do instrumento Estudo de Impacto de Vizinhança requer pensar melhores aprimoramentos científicos e metodológicos para sua condução, sem, contudo, perder de vista a multiplicidade de escalas territoriais, paisagens e dinâmicas urbanas, para que os municípios compatibilizem o instrumento às suas realidades.

Requer, também, não olhar o instrumento de forma isolada, mas, ao contrário, contextualizá-lo frente aos demais instrumentos de política e de licenciamento urbano-ambiental, em um contexto de forças predominantes do mercado sobre as dinâmicas urbanas, para que se implemente, de fato, uma compreensão prévia do território, atrelada a outros estudos e instrumentos complementares, evitando ao máximo os impactos cumulativos e os passivos socioespaciais.

O EIV, dentro do escopo do licenciamento urbano-ambiental, deve ser encarado como uma ampla possibilidade social e política de mediação dos conflitos. Desse modo, planejadores urbanos, juristas e promotores, gestores e técnicos do poder público, empreendedores e, sobretudo, novos movimentos e grupos sociais precisam reconhecer o seu papel nos processos de uso e ocupação do território brasileiro e atuar em um movimento de compreensão acerca de novas possibilidades de governança, de um trabalho de formação e sensibilização e de renovação para a melhoria da gestão urbana e ambiental do país.

\section{Agradecimentos}

Este trabalho contou com o apoio da FAPESP (Processo no 2015/03449-4, Fundação de Amparo à Pesquisa do Estado de São Paulo - FAPESP).

\section{Referências}

Araújo, R. P. Z. de, \& Campante, A. L. G. (2017). Estudo de Impacto de Vizinhança: questões e desafios de sua implementação. Reflexões a partir da experiência de Belo Horizonte. In Anais do XVII Encontro Nacional da Associação Nacional de Pós-Graduação e Pesquisa em Planejamento Urbano e Regional. (p. 1-20). São Paulo: ANPUR.

Bitoun, J., \& Miranda, L. (Orgs.). (2009). Tipologia das cidades brasileiras. (Conjuntura urbana, 2). Rio de Janeiro: Letra Capital: Observatório das Metrópoles.

Bucci, M. P. D., Saule Júnior, N., Arzabe, P. H. M., Frischeisen, L. C. F. (2001). Direitos humanos e políticas públicas. (Cadernos Pólis, 2) São Paulo: PÓLIS.

Brasil (1981, 2 de setembro). Lei n.6.938, de 31 de agosto de 1981. Dispõe sobre a Política Nacional do Meio Ambiente, seus fins e mecanismos de formulação e aplicação, e dá outras providências. Brasília: Diário Oficial da União, seção 1.

Brasil (1989, 29 de junho). Projeto de Lei n. 181, de 1989 (do Senado Federal) PLS n. 181/89. Estabelece diretrizes gerais da Política Urbana e dá outras providências. Diário do Congresso Nacional, Brasília, N. 2, 29 jun. 1989.

Brasil (1990, 9 de outubro). Projeto de Lei n.5.788, de 1990 (da Câmara dos Deputados) PL n. 5788/90. Estabelece diretrizes gerais da Política Urbana e dá outras providências. Diário do Congresso Nacional, Brasília, N. 1, 10 out. 1990.

Brasil (2001, 11 de julho). Lei n.10.257, de 10 de julho de 2001. Regulamenta os arts. 182 e 183 da Constituição Federal, estabelece diretrizes gerais da política urbana e dá outras providências. Brasília: Diário Oficial da União, seção 1.

Cassiano, A. M. \& Peres, R. B. (2016). Diretrizes e critérios para a regulamentação e implementação do Estudo de Impacto de Vizinhança (EIV) no município de São Carlos, SP. In Anais do 7º Congresso Luso Brasileiro para o Planejamento Urbano, Regional, Integrado e Sustentável: Pluris. (p. 1-12). Maceió: Viva Editora.

Costa, H. S. (2008). A trajetória da temática ambiental no planejamento urbano no Brasil: o encontro de racionalidades distintas. In: COSTA, G. M.; MENDONÇA, J. G. (Orgs.). Planejamento urbano no Brasil: trajetória, avanços e perspectivas. Belo Horizonte: C/Arte.

Fernandes, E. (2013). Estatuto da Cidade, mais de 10 anos depois. Rev. UFMG, Belo Horizonte, 20(1), 212-233. 
Glasson, J., Therivel, R., \& Chadwick, A. (1999). Introduction to Environmental Impact Assessment. 2. Ed. London: UCL Press.

Harvey, D. (2014). Cidades rebeldes: do direito à cidade à revolução urbana. São Paulo: Martins Fontes.

Hoshino, T. A. P., Wultrich, F., Jacobovski, A., Faggion, A., Auler, M. M. \& Becher, J. (2014). Do Estudo de Impacto de Vizinhança e de sua impostergável regulamentação e implementação no Município de Curitiba: análise comparativa e recomendações. Nota Técnica. Projeto Cidade em Debate (UFPR/UP/MPPR).

Instituto Brasileiro de Geografia e Estatística - IBGE. (2014). Perfil dos municípios brasileiros 2013. Rio de Janeiro: IBGE. Pesquisa de Informações Básicas Municipais. Recuperado em 16 de março de 2018, de www.ibge.gov.br.

Instituto Brasileiro de Geografia e Estatística - IBGE. (2016). Perfil dos municípios brasileiros 2015. Rio de Janeiro: IBGE. Pesquisa de Informações Básicas Municipais. Recuperado em 16 de março de 2018, de www.ibge.gov.br.

Instituto de Estudos, Formação e Assessoria em Políticas Sociais - PÓLIS. (2006). Política pública como garantia de direitos. Boletim REPENTE. N.26. Recuperado em 5 de janeiro de 2019, de www.polis.org.br.

Instituto de Pesquisa Econômica Aplicada - IPEA. (2018) Avaliação de políticas públicas: guia prático de análise ex ante. V.1. Brasília: Ipea, 2018. Recuperado em 6 de janeiro de 2019, de www.ipea.gov.br.

Klink, J. \& Souza, M. B. de. (2017). Financeirização: conceitos, experiências e a relevância para o campo do planejamento urbano brasileiro. Cad. Metrop., São Paulo, 19(39), 379-406. https://doi.org/10.1590/2236-9996.20173902.

Maricato, E. (2000). Urbanismo na periferia do mundo globalizado: metrópoles brasileiras. São Paulo em perspectiva, 14(4), 21-33.

Marques, J. S. (2010). Estudo de Impacto de Vizinhança: uma análise crítica feita por meio dos relatórios de impacto de vizinhança apresentados no DF (Dissertação de mestrado). Faculdade de Arquitetura e Urbanismo, Universidade de Brasília, Brasília, DF.

Ministério Público do Paraná (2018). Controle de Edificações e Licenciamento Urbanístico. Recuperado em 29 de março de 2018, de http://www.urbanismo.mppr.mp.br.

Peres, R. B., \& Cassiano, A. M. (2017). Inter-relações entre o Estudo de Impacto de Vizinhança (EIV) e o Estudo de Impacto Ambiental (EIA): perspectivas e contribuições às políticas públicas ambientais urbanas. In Anais do XVII Encontro Nacional da Associação Nacional de Pós-Graduação e Pesquisa em Planejamento Urbano e Regional. (p.1-20). São Paulo: ANPUR.

Pilotto, A. S., Santoro, P. F., \& Freitas, J. C. (2013). Estudo de Impacto de Vizinhança: desafios para sua regulamentação frente ao caso de São Paulo. In Anais do VII Congresso Brasileiro de Direito Urbanístico. (p. 1-20). São Paulo: PUC/SP.

Quinto Jr, L. de P. (2003). Nova legislação urbana e os velhos fantasmas. Estudos Avançados, 17(47), 187-196. https://doi.org/10.1590/S0103-40142003000100011.

Ribeiro, L. C. de Q., \& Diniz, N. (2017). Financeirização, mercantilização e reestruturação espaço-temporal: reflexões a partir do enfoque dos ciclos sistêmicos de acumulação e da teoria do duplo movimento. Cad. Metrop., São Paulo, 19(39), 351-377, http://doi.org/10.1590/2236-9996.2017-3901.

Rolnik, R. (2000). Instrumentos urbanísticos: concepção e gestão. Campinas, PUC. Óculum Ensaios, 1(1), 5-12.

Rolnik, R. (2015). Guerra dos lugares: a colonização da terra e da moradia na era das finanças. São Paulo: Boitempo. $423 p$.

Sánchez, L. E (2013). Avaliação de impacto ambiental: conceitos e métodos. 2.ed. São Paulo: Oficina de Textos.

Schasberg, B. (2011). Estatuto da Cidade, EIV e a Gestão Democrática no Planejamento Urbano. Texto elaborado para o Seminário "Estudo de Impacto de Vizinhança - e a lei do EIV em Porto Alegre". Porto Alegre, Secr. do Planej. Municipal/ MPE Rio Grande do Sul. (mimeo). Recuperado em 16 de março de 2018, de http://lproweb.procempa.com.br/pmpa/prefpoa/spm/usu_doc/bennyschasberg-eiv_e_ec_pdf

Schvarsberg, B., Martins, G. C., Kallas, L., Cavalcanti, C. B., \& Teixeira, L. M. (Orgs.) (2016). Estudo de Impacto de Vizinhança: Caderno Técnico de Regulamentação e Implementação. Secretaria Nacional de Acessibilidade e Programas Urbanos, Programa Nacional de Capacitação das Cidades e Universidade de Brasília. Brasília: Universidade de Brasília. 98p. 
O Estudo de Impacto de Vizinhança (EIV) nas regiōes Sul e Sudeste do Brasil

Wood, G. Environmental impact assessment. A comparative review. Harlow: Longman, 2a. ed., 2003.

Editor: Paulo Nascimento Neto

Recebido: Ago. 20, 2018

Aprovado: Jul. 04, 2019 